\title{
The "Space" of Religion in the Assessment of Asylum Applications
}

\author{
Laura Zanfrini
}

As anticipated in the previous chapter, one of the main purposes of this part of the study is to inquire how the process of asylum applications' assessment leads to the emergence and the acknowledgement of all those aspects connected in many ways to asylum seekers' religious belonging. In Chapter 9, we have illustrated the Italian legislation in force, in its contents and its weaknesses. Here, we will examine the attitude of the various stakeholders involved, with an attempt to provide an answer to the following question: do these aspects constitute a relevant variable in acknowledging the need of protection, possibly even beyond what established by the legislative framework?

This goal implies having to deal with a bigger question regarding the criteria useful to define the "borders" of forced mobility, which helps to distinguish between voluntary and forced migrants. As it is well known, this distinction, on which migratory regimes have been traditionally based, today is strongly challenged from both a political and an ethical point of view. The authors of Chapters 2 and 4 have already analyzed some of the main issues involved, and the manner in which those have been influencing the legislative evolution at both the international and the European level. Here, it is useful to remember that it is exactly because of the progressive inclusion of new categories of people and circumstances into the systems of protection that the line between voluntary and forced migrations has become increasingly porous and disputable, to the point of putting in question its own existence (for a deeper analysis, see Zanfrini, 2019). Our hypothesis is that this trend influences the attitude of all the actors of the reception system, from the commissioners in charge with the asylum demands' evaluation to the operators who "prepare" the asylum seekers for the interview.

$1 \quad$ Religion(s) and the Borders of Forced Mobility

As we have already described (Chapters 3 and 9), unlike other types of migrants, variously defined by the laws of individual countries, the refugee figure is based on a precise -internationally recognized- legal institution, contained 
in the Declaration on the Status of Refugees. However, given the growing complexity of human mobility at the global scale, nowadays asylum seekers resemble less and less the Ideal Type of refugee inspired by the 1951 Geneva Convention. First of all, forced migration has usually a collective, not individual, configuration (Zolberg, 1989), and reflects a shared need to flee from situations of crisis that have unpredictable consequences and evolution. Moreover, the threat from which one may flee is not necessarily the State, but it may be represented by an agent of civil society, or even by a family member, as we have also observed in the previous chapter. Furthermore, the fear of persecution no longer only concerns imprisonment, but it also refers to the widest range of human rights, including, for example: the fear of being subjected to sterilization or excision or of being imposed into forced marriage, violations of the rights of homosexuals, or even survival jeopardized by only announced environmental catastrophes (Black et al., 2011; Kumin, 2007; Pickering, 2011). Migration is sometimes not only forced (i.e. due to the lack of other possibilities of survival and development), but even compulsory, which is triggered by various forms of trafficking and enslavement. Moreover, because of its circumscribed nature, the Convention's definition of "refugee" is poorly equipped to protect people who cross international borders in the context of wars and civil unrest (IOM, 2017). Finally, protection systems have been built in compliance with a male archetype, a circumstance that makes said systems inadequate to meet the needs and the specific risks posed to female migrants (Pickering, 2011). Not to mention their inadequacy in front of the growing incidence of minors, sometimes unaccompanied, who are the most vulnerable among the vulnerable (Valtolina, 2014). This complex scenario -amply mirrored in the characters of migration fluxes currently addressed to Italy- must be taken into account in order to apprehend the relevance of various aspects connected to religions, in their interrelation with other variables such as gender, age, family status, sexual orientation, and so on.

Religion is one of the causes of persecution specifically evoked by the 1951 Geneva Convention, together with race, nationality, belonging to a given social group, and political opinions. However, its role must to be contextualized within the complex reality of contemporary human mobility, and particularly within the so-called migration-asylum nexus: this expression describes how fluxes due to different reasons and inscribed in different legislative regimes display themselves through similar modes, such as through the same routes and entry channels (including the demand for asylum), within the same international context. Hence, the relations among different religious groups, and their unpredictable evolution, are on the background of many collective arrivals; moreover, they are strictly interconnected with ethnic and socio-economic variables, as we have commented in the previous chapter. As 
clearly demonstrated by the following statement, this circumstance can result if not in the "omission" of the religion issue, surely in the "temptation" to precategorize those asylum seekers whose claims are based on religious reasons according to their gender, country/region of origin, and, paradoxically, right on their religion

In the case of migrants coming from North-East of Nigeria, if Christians are considered refugees for the Geneva Convention, if Muslims are distinguished according to the areas. Women are refugees by themselves. Women in southern Nigeria are Christians, but the problem is the trafficking of human beings. The fear of Islamic fundamentalism as a drive to emigrate has never been connected. A theme to think about, but I think the problem of Nigerians is not religious. (Woman - Official of the asylum seekers' reception system)

This declaration, on the other hand, seems to suggest that the "mere" fact of coming from a potentially risky context can be a reason to become eligible for international protection. In this way, Christians escaping from Nigeria, particularly in the case of women, are offered a special treatment, despite the fact that the same expert had observed that "the problem of Nigerian women is not of religious nature", and despite the fact that most of them come from regions different than those actually under the control of Boko Haram (but where its expansion is dreaded).

Furthermore, protection is envisaged also in the case of those who do not belong to established religions, as in the case of adepts to religious sects. According to the testimonies of our key informants, as we have already reported, an increasing number of Chinese, women in almost all the cases, declare to be victims of various forms of persecution because of their affiliation to "God Almighty", a Chinese sect which sustains that Christ has come a second time, with a female body; he/she is still living, but no one knows where he/she is now.

(...) girls who need immediate care of souls, a direct relationship with the Pastor or the Pastora (the female pastor, author's note), because they need to tell their own story and be directed to those mechanisms that will allow them to have a residence permit. They are asylum seekers for religious reasons (...). Young girls ... from their stories it is clear that they have been persecuted; in China there are Churches of State, the others are out of the norm, so they are persecuted. These girls are part of domestic Churches, tiny churches, which are in homes, but neighbors are spies. The girls are arrested, they try to collect money and they come to 
Milan, Turin, Florence, where there are other people who can give that logistic support that they pay. (Woman - Religious leader - Evangelical Christian)

However, as pointed out by this executive of the Italian reception system, it is extremely difficult, not to say impossible, to grasp the contexts of origin of asylum seekers in all their complexity, despite the possibility of consulting the database made available to them $(\S 2)$. And adequately classify actors, reasons and consequences of persecution on a religious basis. While unanimously declaring their adherence to a guaranteed approach, the key experts involved in the study reveal all their difficulty in dealing with this issue and, at times, the tendency to be guided by preconceived visions of the importance to be paid to the different religious affiliations, to the point of crossing the risk of ethnocentrism. Thus, it is interesting to observe how, in the formulation of this expert, "tribal rites" are downgraded to the role of something that cannot be considered as a "real" faith.

The situations are varied so it is impossible to make a unitary reading. Example: Pakistani boy (Shiite) who had fallen in love with a Pakistani girl (Sunni). The Imam refuses to celebrate the marriage because it would have polluted the purity of the faith. The boy goes to a civil court, but a commando at a checkpoint kills the girl. Today in the Islamic area there are phenomena of persecution against the Azeris who are worse than those towards the Christians (...). In many countries there are prohibitions to enroll children in school, to practice trade. There are areas in which one is persecuted for being Christian, areas in which there is an element of discrimination, or where situations of confrontation occur due to animistic phenomena, for which it is not clear whether it is a problem of faith or linked to tribal rites. (Man - Officer of the asylum seekers' reception system)

It is quite clear how, once confronted with given kinds of narratives, the distinction between forced and voluntary migration becomes even more porous and arbitrary. What's more, it frequently happens that the same narrative is repeated in a quite identical manner, thus feeding the suspect of its bogus nature.

There are very few credible religious claims. The interviewer's task is to investigate not only what is being told, but also to understand if the 
person is at risk of persecution regardless of what he tells. (Woman Officer of the asylum seekers' reception system)

We will return to this phenomenon further on, since it is one of the most critical points. What is interesting to note is that it is explicitly denounced by the migrants themselves, as in this testimony where the interviewee observes how phenomena like human sacrifices do exist in certain African regions, but in a number surely lower than the one reported to the commissions.

(...) you know when people come to Europe and seek for asylum or international protection, they did something to tell the commission ... for the commission to believe in them so if it happens to one person and person comes and tells in front of the commission: "This is my story", then the next person is like: "Oh, that's what that person said, so I'll go and tell the same story" and he goes and tells the same story, and you know it's just like my own story when I told my own story, I was told that -not by commission but by other people- that Nigerians come and they said that left Nigeria because of Boko Haram and some of them don't even know anything about Boko Haram, they don't even live in the northern part of Nigeria, they don't even speak the language that we speak in the northern part of Nigeria, so what do you ... they have never been affected by Boko Haram, but because they know that other Nigerian have got the permission or international protection because of their experiences of Boko Haram they feel like, ok I'll tell the same story. So the story of human sacrifices, yes, it's possible that some people have actually faced human sacrifices, but if you interview maybe 20 people from Edo State and 15 tell you that they left because of human sacrifices then it is a lie. Even the chances of you meeting somebody who was involved in human sacrifices and escaped is maybe one in two hundred, if you ask me ... it's just that everybody needs a story to give ... but I don't think that human sacrifices happen like that in Nigeria, no it doesn't, it's very rare. (Young man Nigeria - Christian)

Another Nigerian interviewee is even more drastic when he affirms that Europe is a powerful pulling pole, even independently of effective "true" reasons to migrate; so attractive to encourage a widespread tendency to lie:

I don't know about people that go there, tell lies and have documents, but I know that people tell lies. Most people lie, everybody lie. So most people 
lie to get the documents, because most of the times, most of us, most Nigerians, most blacks, they don't leave home because they have problems, that's the truth, they leave home because they think that Europe is beautiful, Europe is free, you can live a free life, you can be happy ... (Man Nigeria - Catholic Christian)

The risk of an instrumental reference to religious arguments, by any "bogus" asylum seeker who tries in this manner to "confuse" the commissioners, has repeatedly emerged during the focus groups. The recurrence of narratives identical to each other is often referred to as a clear symptom of this phenomenon. In any case, despite the different perception of some applicants (who may fear that this circumstance would negatively influence the commission approach, making it more suspicious), our key informants have unanimously concluded that this risk cannot influence the assessment activity.

The Court of Cassation has clearly said that repetition does not mean that there is falsehood. It is up to the one who decides to do the necessary investigations. It is not that if the story is repetitive then it is not true. Many may have been involved in Boko Haram's village fire. Group persecution is a true, real phenomenon. (Man - Expert)

In this regard, a point repeatedly underlined is that the commission must always evaluate each single position, and encompass all the possible kinds of violations, included those quite impossible to prove. One case in point is represented by the declaration of a conversion to a minority religion not manifested publicly because of the fear of becoming a victim of harassment (with very few exceptions, our informants have excluded the possibility or recurring, in these situations, to the help of religious authorities in order to obtain some "proofs" of the feasibility of the conversion).

Then comes the question that has already been dealt with by the Court of Justice of the European Union: whether or not it is obligatory for the foreigner to demonstrate that he has already exercised his religious confession in his homeland. And the Court has rightly said: but not even for an idea, because in that country a minority confession is persecuted but if I declare my membership I will be persecuted. So it is clear, says the Court, we cannot force ourselves to submit to the persecution. Religious freedom, like other positive liberties, entails the right to manifest or not to manifest, freely to say one's own belonging. And also the right to keep it confidential (...). 
They can say that the request must be rejected only because if the foreigner remained in his own country without demonstrating, he would not be persecuted. Because, says the Court, it would end up legitimizing persecution and/or legitimizing an abusive restriction of religious freedom that is guaranteed in our legal systems. (Man - Expert)

Finally, the suspect of a "bogus" use of religious arguments is widespread among both the experts and the officers in charge with the applications' assessment. However, even if they are aware that this phenomenon is playing a specific role in delegitimizing the asylum system in the eyes of public opinion, they assert pragmatically that this risk is part of the "rules of the game". Or, as suggested by a UNHCR officer, it is even a further signal of a progressive erosion of the distinction between forced and voluntary migration:

(...) an expansion of secure migration channels supported by local communities is needed. Where there is a risk of life, those with religious responsibility often become unbalanced and it is delicate to enter the realm of the conversion process. (Woman - UNHCR officer)

Despite the fact that, today, asylum seekers are mainly coming from Islam-majority countries, it is decidedly more frequent to find a reference to the violation of religious rights in the applications of asylum seekers affiliated to other religious traditions, starting from the Christian ones. The most quoted cases concern: Chinese (female) migrants who declare to be victims of persecution because they belong to Christians sects (in particular to the Church of God Almighty), Christians flying from Northern Nigeria, and Coptic Egyptians and Iranians converted to a different religion than the Islamic one.

(...) we find ourselves managing an emergency in which a series of complex factors exercise their influence. Some religious claims in the pure sense paradoxically at this moment are only advanced by the Chinese. Chinese who adhere to Christian sects. In the office, I have a package of applications presented by women who do not know how to evaluate because they have problems of dialogue and of information on the country of origin. (Woman - Official of the asylum seekers' reception system)

This circumstance does not cause Christian applicants to experience a positive discrimination when they enter the procedure. As we will describe in the following paragraphs, as any other applicant, they have to face a system that, 
despite a genuine intention to cover all the situations connected to a violation of religious rights and religious freedoms, suffer different forms of bias.

Actually, independently of their religious membership, the interviews with migrants provide considerable evidence, as we have seen in the previous chapter, of the many religious-connected factors that concurred to the decision to migrate, even though only in a few cases these factors are emphasized during the dialogue with the commissioners. Not to mention the fact that most of our sample entered Italy and obtained his/her stay-permit through a procedure different than the request for protection: a further signal of the tremendous gap between contemporary migration trends and established migratory schemes. On the other hand, the personnel in charge with the analysis of the asylum applications seems to be particularly sensitive not only with those situations in which religion appears to be the direct "cause" of migration, but also with those that we can define as indirect religious-connected causes of (forced) migration, even if they could be not easily acknowledgeable from a formal point of view. This is particularly true as far as those situations in which the living conditions turn out to be strongly compromised by the presence of dictatorial or autocratic regimes, based on a fundamentalist view of religious precepts...

The persecution must be considered in an enlarged dimension. Why do people leave the Middle East? There are fundamentalisms (I think about Syria), but also dictatorial systems that exploit the fear of the Islamist adversary (Egypt: there is no real persecution, but civil war). One can thus see the effect of religious fundamentalism in perpetuating autocratic regimes: migratory flows not to escape persecution, but a religious factor, however, is at the origin. (Man - F BOs leader - Catholic)

...or where, in the name of religious teachings and guidelines, strong limitations to the personal freedom are imposed, particularly to women and other subordinated groups, thus transforming religion into a mechanism of social and political control:

We evaluate to investigate the case of Nigerian women. The Islamist fundamentalist presence hostile to women and a growing history of women's migration cannot be by chance. But to what extent are these factors also linked to the unconscious level? The fact is that I want to survive, and it is difficult to survive in a certain country if you are a woman; and if you are Muslim, but not in the way the fanatics want it. (Man - Religious leader - Muslim) 
Furthermore, the focus group discussions took in consideration those applications referring to a possible involution of religious minorities' conditions, connected to the current geo-political context. The most quoted case is that of Nigeria, with reference to asylum seekers coming from geographical areas that are still outside the control of Boko Haram - which they fear will expand its territory even further.

All the key informants have agreed with the conclusion that the mere risk of future persecution is a sufficient argument to receive a demand; also because it is definitely rational to search protection before it will be too late for escaping! (the many Jews who fled from Europe at the dawn of the Nazi delirium are proof of this, since many others did not have time to seek shelter).

Finally, what has clearly emerged from the study is that the Italian system of protection (including in this expression all the categories of key informants involved) seems to be globally immune from the influence of the present context, where applicants are increasingly perceived as bogus asylum seekers who "use" religion as a pretext to produce false chronicles; besides, said system does not even seem to be prejudiced by the outcomes of previous demands, most of which had been actually rejected (see Chapter 10, §1). The key informants have stated that every kind of persecution and violation, directly or indirectly linked to the applicant's religious profile, must be seriously taken into account, regardless of the risk of a forged chronicle. Since religious freedom is defined as a fundamental human right, every kind of violation (from a violent persecution to the simple fear of declaring one's own religious beliefs) must be covered by the procedures of protection. The same should happen as far as the mere risk of persecution is concerned: as we noted above, many informants evoked the historical antecedent of Jews, reminding that only the ones who had been welcomed before the mass deportation to concentration camps had the chance to escape from persecution and survive.

Lastly, the commissioners are expected to explore this issue whenever the situation of the country of origin, as well as the "tone" of the account provided by the applicant, make it pertinent and relevant. Very few of the key informants have sustained that, since we are dealing with a very intimate and personal sphere, it is recommendable to avoid any arguments not spontaneously emerged. On the contrary, most of the experts involved think that, at least when the situation of the sending country makes it pertinent, it is always advisable to scrutinize this issue. In other words, even if the applicant does not refer specific facts connected to his/her religious identity and beliefs, it is the commissioners who have to examine them, since it would represent an important aspect in order to decide on either the approval or the denial of the request. 
Even if the applicant does not state a religious motivation, because perhaps he is not aware that this may be a reason, the commission, which has knowledge of the situation in the country of origin, highlights it and has a duty to investigate that aspect. (Man - UNHCR Official)

Despite all this, two main critical aspects have emerged from the fieldwork. The first one, on which we will focus the attention in the next paragraph, is of a "technical" nature. The second one, object of the following one, has to do with the political/ideological dimension of the issue and with the manner in which it feeds back on the evaluation setting.

\section{$2 \quad$ Technical Biases}

Given the extraordinary complexity of the current scenario, it is easy to understand how the different actors of the reception system, including the commissioners in charge with the applications' assessment, lack a comprehensive knowledge of the situations of both origin and transit countries, not to mention the intra-national variety of risks and problems. It is not a coincidence that they have openly admitted their difficulty in talking about subjects that they do not completely master. According to their reading of the subject, the religious landscape of origin countries is not only tremendously complex; it is also "filtered" by the ambiguous and embellished representations diffused through the media system, which can influence the commissioners' perceptions -despite their engagement to be neutral-or even induce them to underestimate the risks on which people coming from given countries were exposed (we will return to this point in the next paragraph).

First of all, as stressed by this interviewee, Italians' perception suffers from a strong cultural distance with respect to the sending countries social landscape:

Interviewer: For us, in Italy, it is very difficult to believe that they really perform human sacrifices. Because we think that...

Do you know the reason why it is very difficult for you to believe? Because you are far from Africa. Do you understand? You are very, very far from Africa. When you watch television and see what is happening in Nigeria you will believe! You are in a country that respects the law. If Nigeria respects the law, all these things would not happen in Nigeria. Italy respects the law, they respect their law. You can't see Italy fight, I've never seen Italy fight. They can talk. But for Nigeria everything is possible there, for them to do. To kill somebody is nothing to them. When you watch 
television, what is happening in South East, now, for my region, what is happening there, even Italy's Government knows what is happening in Nigeria. (Man - Nigeria - Christian Pentecostal Church)

Another critical point has to do with the manner in which religion and spirituality are understood and experienced across the various socio-cultural contexts. Just to cite a case in point, Catholicism in Armenia is not the same as Catholicism in Italy; rituals, prayers, devotions are deeply embedded in the local history and traditions. Therefore, when the commission puts questions based on the "Italian version" of Catholicism, they can result understandable for an applicant coming from a different milieu. This kind of "cultural bias", on its turn, is just the first piece of a mosaic of a deeper ideological bias that we will further discuss in the next paragraph.

Technically, the regulations in force offer the possibility of resorting to a cultural mediator with the aim to feel the gap between the applicant's experience and feelings and the commissioners' mind-set. However, many informants have observed that, despite being indispensable, the use of a cultural mediator (or, quite often, a simple translator) turns into a supplementary problem, since he/she might be considered to be not completely trustworthy when dealing with specific topics. The following testimonies provide some emblematic examples of how, in the perception of applicants who are waiting for the interview, current procedures are not reliable enough to protect migrants from given countries who have had to face persecution to the point that they fear they might find it in the destination country too:

I'm still waiting and also nowadays I see the result is negative for so many persons from Pakistan, also Christians, one of my friends went to Commission two times but he was rejected. He was a Catholic Christian.

Interviewer: Did he tell you why? Was he able to tell his story completely or what?

He told his story completely but sometimes there are Muslim translators/mediators so...

Interviewer: Do you think they are Muslims?

Yes, they are Muslims, even when we applied for asylum we asked for a Christian translator but we get our reply that there was no option for us to have a Christian mediator. (Man - Pakistan - Catholic Christian)

I'm worried. Here in Milan, they do not make you tell the story well, they interrupt you, there is little time. Then the interpreters are Chinese and I heard from confreres who sometimes do not translate what you say because they think it is not right and so they interrupt us and do not tell the 
committee. Some things are not translated. (Woman - China - Church of God Almighty)

Afghan Muslims think that Pakistan's Muslims are not well, but I do not know why, because some time ago, 20, 25 years ago, Afghans came to Pakistan for asylum, when there was war and because sometime before, 25 years back, they came to Pakistan as refugees, but when they were there, they were going to go back to their land, so now we have a problem, so when there are mediators from Afghanistan there are problems for Muslims from Pakistan...

Interviewer: And did you ever talk to a Muslim from Pakistan who had a mediator from Afghanistan?

Yes, I have one friend who had one mediator from Afghanistan about one year back, he was ... he spoke a different language so it was difficult for him. (Man - Pakistan - Catholic Christian)

On the other hand, even if in good faith, when they lack a specific competence about religious matters, translators cannot be able to decode concepts and institutes embedded in a specific religious tradition and milieu. As observed by a key informant (an attorney in charge with the assistance of asylum seekers), a non-believer translator can encounter many difficulties in decoding religious and theological concepts and in rendering them in a different language, understandable by the commissioners. The same is obviously true when it comes to translating for the applicant the questions posed by the commissioners. An expression such as "Jesus' transfiguration" (which can be used by the commission in order to test the authenticity of a conversion) can be impossible to translate by a non-Christian translator (but also by a Christian translator who is not so familiar with religious matters). Only very professional and trustworthy translators admit their inadequacy in this kind of circumstance, eventually suggesting they should ask for the help of an expert (this possibility is permitted by the legislation, even though it is scarcely used by the commissions, due to the high number of applications that have to be evaluated).

Religious beliefs, identities and ways of life are definitively a sensitive topic. As a matter of fact, "religious" variables are in many ways interconnected with ethno-racial, political, and economic ones, as we have amply observed. Unequivocally pertinent, from an empirical point of view, this circumstance can turn into a "rational stratagem" to avoid facing this specific issue.

Encouraged to deepen the analysis of this topic, our key informants have described the religious experience as shaped and structured not only by the political and cultural context of the sending community, but also by the sex/ 
gender of each asylum seeker, his/her age and the specific phase of his/her life cycle, his/her age cohort (since many sending countries have been recently characterized by a significant evolution/involution of their religious landscape), not to mention his/her level of education (only well-educated applicants are normally able to understand complex concepts and expressions).

Some Syrian refugees, who have a motivation to escape in which there is religious relevance, interpret this cause differently than the previous generation of Syrian refugees. The interpretation of one's right to freedom, one's own religious interpretation, is conceived in a different way. The context of Syria has changed and the type of interlocution must also change. (Man - Religious leader - Muslim)

In an "ideal world" this would imply, for example, the possibility to resort to a "specific" cultural mediator, or to adopt an individualized approach, thus permitting each applicant not only to describe his/her own experience and feelings, but also to elaborate them. Just to cite an example, people coming from specific contexts can find it impossible to discuss sensitive subjects with someone of the opposite sex. For all these reasons, the discussion within the focus groups has reached the conclusion that dealing with religiosity and spirituality would require specific hearing techniques, different from those employed to talk about less sensitive topics.

Then there is the theme of re-reading the motivations that lead to the problem of persecution. Religious confession is a trait of the person who in some places leads to discrimination, such as ethnicity, lineage, family. But there is difficulty in telling it (...). It is hard to go deep when the motivations are complex. The persecution for religious reasons must be explained, contextualized. Explaining that a moderate Muslim who is persecuted by extreme Islamist fringes is difficult. The theme is there, I do not know if it can be pigeonholed: everyone has his own path. (Woman - Local government official)

Ultimately, this issue seems to be paradigmatic of the challenge of processing an extraordinary variety of human experiences through standardized procedures; not to mention the short time devoted to each interview, which does not offer the possibility to deeply analyze individual experiences and feelings.

There are some guidelines, but in Italy we are subjected to an immense logistic challenge for the number of languages and interpreters we need, 
for the time, etc. It is not that we do not know what would be better and more appropriate, but we need a balance with what is reasonable and we are able to do in fact. The interpreters, the commission, deal with issues which do not need only geopolitical competences, since they are characterized by a detail of complexity that is not said to be managed. (Woman - FBOs operator - Catholic Christian)

Besides technical biases, our study led to the emergence of other kinds of biases, which are connected to various contextual variables.

First of all, the reception system -starting from the commissioners-does not always possess a suitable knowledge of the complex religious scenario of the asylum seekers' origin and transit countries. Testimonies reported in the previous chapter provide ample evidence of this complexity. As we have already discussed, the people involved are commonly aware of this critical issue, which is somehow irremediable, despite the significant efforts made in order to enrich the level of information and competence of the commissioners.

However, evidence provided by the study support the hypothesis that we also have to deal with the risk of a "cultural bias". Not only because, as we have already described, it is tremendously difficult to decode highly sensitive experiences and feelings, such as the religious ones, in a way that would turn out to be comprehensible even to a foreign examiner. What's more, migrants and asylum seekers sometimes bring with them - or speak about- religious beliefs and practices that are completely far from the Italian mentality. As observed by this Cameroonian intercultural mediator, established perceptions about religious problems - such as a supposed conflict between Muslims and Christians-tend to dominate common opinion, thus banishing many local varieties of "religious" traditions, precepts, and duties.

(...) is the ignorance of those traditional factors, because everyone thinks in terms of Muslims and Christians conflict, they do not know that in the tribes there are these things that happen, as I for example in my country, if you have been chosen as future king, you cannot run away from that responsibility, they look for you everywhere, so maybe if someone runs away, they come here, they say: "But it cannot be true", instead it often happens that there is also someone who escapes from that responsibility, to be ... it is a traditional responsibility and there are perhaps Christians who do not want to go into that too spiritual thing in the village, so they prefer to leave, but they will tell you: "It cannot be true here". So it's a little 
difficult to understand the type of situation, if they do not go right on the field to see ... (Man - Cameron - Intercultural mediator in the reception system)

One case in point is represented by those applicants who declare problems connected to their belonging to communities devoted to animistic cults. Since the latter can sound "exotic" (if not primitive) to a Western (Italian) mentality, it is easy to understand how this case, if not in the applicants' perception, can be underestimated. It is not a coincidence that in the current anti-migrants' discourse, the applicant who declares to have escaped because of the risk to be sacrificed by his/her community's members (or to be obliged to sacrifice someone else) has become a sort of paradigmatic example of the bogus nature of many applications. As a matter of fact, besides having fed the stereotypes about non-Western religious customs and backgrounds, the recurrence of this kind of chronicle has contributed to "devaluate" the claims based on religious arguments.

Conversely, various key informants have indicated a second critical phenomenon, by signaling that many asylum seekers would tend to skip religion, if not to omit it during the interview. Europe and Italy are actually perceived as secularized societies, to the point that omitting "this part of the discourse" is sometimes conceived as a strategic behavior, one that raises the possibility for the demand to be approved. According to a shared perception, commissioners would be stereotypically considered as unsympathetic towards religious arguments. As denounced by this Nigerian man, in the present Italian cultural landscape, other issues -such as homosexuality- would encounter much more consideration. According to his testimony, this would even involve a sharp discrimination towards asylum seekers whose claims are founded on religious motives. Probably in an unconscious manner, his experience reflects a common trend in democratic societies, where in the name of an "equality paradigm" in social consciousness, religious rights are too often given little weight (Durham Jr., Thayer, 2019).

I explained to them the reason why I came to Italy. When I talked about Christian religion, that I had religion problems, they wouldn't listen, because I think they don't know about it, but when you talk about maybe lesbian, that sort of things, they give you documents fast, but this is the reason why even if I told them they gave me the negative one.

(...) In my opinion ... They say that when you go to the commission, they take some time to investigate, but ... my understanding is that this world that we are living in belongs to the devil, so time will come that God will come and take his people to Heaven, so if I believe in my own 
understanding that if you have problems that concern God in Italy they don't, they don't take you seriously. I don't believe they investigate ... if you say that you want to become Christian and you left your country, this makes them upset. But if I was homosexual now, I go to the commission and I tell them I'm homosexual, now, they give me five-year shop shop, because I have many friends, and also friends when I was in the camp before, because they are homosexuals, they go to commission and most times they had documents, but when you talk about Christians, and you come for religion, they don't even want to listen. (Man - Nigeria - Catholic Christian)

On the other hand, commissioners are sometimes stereotypically perceived as "Catholics" -since Italy is known as a Catholic country worldwide- and therefore prejudicially deemed as characterized by a potentially discriminating attitude towards people belonging to other religious traditions. As it is easy to imagine, in the case of Muslim asylum seekers, this kind of feeling is nourished by a general climate of "Islamophobia", which sometimes would encourage applicants to keep their religious sentiments. This bias has definitely counterproductive effects, since it fuels the perception of a narrative where something is missing, as observed by various key informants, both Muslims and not Muslims.

The impression is that the asylum seeker, in his complexity and personal tragedy, in having to find the answers to the questions of his interlocutor, adapts himself to the perception of the interlocutors. The interlocutors are mostly Westerners, officials, insensitive to the explicit confessional dimension, or Catholics. When some representatives of $\mathrm{xxx}$ (an Islamic FBOS) happened to visit some centers, in particular circumstances, like Ramadan, and no, I had the impression that a psychological adaptation scenario took over: there was the surprise of being in front of me, a Muslim, perhaps Western, and thus discover another type of language and content, but also the need to let off steam. (Man - Religious leader Muslim)

What we have also noticed is that the immigrant too has a distorted view of the West, on how the Muslim religion is accepted, so sometimes the immigrant when he enters does not immediately declare himself a Muslim, because he is afraid that maybe there are prejudices or things like that, and you have to break this difficulty a bit first. (Man - Pastoral operator-Muslim) 
After the attacks in Paris, the fear of receiving denial as Muslims grew; hence the denial of their religious identity during the interviews. (Woman - Officer of the asylum seekers' reception system)

On this regard, it is significant to observe that many -if not all- of the key informants involved in the study share the opinion that religious-connected factors surely play a role bigger than that recorded by official reports and data. Trying to explain this gap, only in very few cases our informants referred to the possible inadequacy of legislative and procedural instruments to grasp the role of religion:

(...) it's just a matter of regulation; they do not fall under this legislation. It is a bit to the conscience of the judge, but of stories like these you hear every day, every day and many are true, many are invented ... In favor of R. we have some documentation, and for this we hope and we trust in the fact that the judge against the documentation brought ... had also brought it to the committee ... I trust that ... R. is always very precise, every question, dates ... is always very precise, does not go into confusion, but unfortunately the judge made us understand that ... there is not really a law in Italy that ... is prepared to evaluate and then give or not the status of refugee for situations of this kind, and unfortunately many refugees arrive here in these circumstances, but (this kind of law) does not exist ... I don't know if I explained myself. (Woman - Italian - Social worker of the reception center)

Decidedly more frequently, the focus was on some characters of the contemporary Italian cultural landscape, which unavoidably influence the asylum system's attitude, the interview's setting included. In general terms, some informants have observed that the contemporary hegemony of economicistic approaches led to understanding migration strategies as they were guided by an economic rationale, thus producing a harsh under-evaluation of any other dimension involved in the decision-making process, starting from the spiritual-religious one. What's more, according to different categories of informants -from religious leaders to operators of the reception centers, and to the same officials of the asylum system- the celebration of secularism - that is, of laicism-, and the political-ideological instrumentalization of religion, are two key aspects of contemporary European and Italian society which newcomers have to face. Furthermore, these aspects even affect the interview's setting, within a paradoxical spiral fueled by specular "modesty" to approach this theme. It is not a coincidence that such disregard would mainly involve 
Christian applicants: a paradoxical consequence of the hegemony attributed to Islam in the public and media discourse about migrants and refugees: what has been defined the Islamization of European immigration debates (Papademetriou et al., 2016). This circumstance would inhibit, according to some key informants, the concern towards other religious traditions (and towards the variety of Islamic traditions as well), through a game of mutual "complicity" between commissioners and asylum seekers. To sum it up, despite its relevance, the religious dimension turns out to be largely "invisible" in this setting, reflecting its invisibility in the public sphere. This circumstance should make us aware of how, if on the one hand it is possible to commit serious persecutions and abuses in religion (and the experience of forced migrants is there to prove it), expelling religion through "secularized" procedures can be just as prejudicial of individual rights.

Finally, this sort of "reluctance" towards religious items -further fueled by a widespread perception of their instrumental use- produces a double counterfactual outcome.

From the asylum seeker's point of view, the fear of not being understood, and eventually rejected:

I'm worried because I know it is not easy for the commission to accept truly that I left my country for religious conflict and if you see I run out of the country for my life so I would be safe and not killed. (Man - Nigeria Catholic Christian)

From the asylum system's point of view -or, to be more precise, the most acute members of this system- the awareness that, by doing so, we run the risk not exactly of violating the asylum seekers' rights, but of lending support to a political instrumentalization of the issue, which loses sight of the most important aspect. As this official says, the instruments of protection, often considered as a threat to "our" Christian identity, or a temptation for possible usurpers, are the seal of our civilization and of our identity.

Very often, we see the tools that protect the migrants as a threat to our status quo. We lose the message that we also help many Christians ... there is no awareness of the situation, which has become more political than technical. (Woman - Officer of the asylum seekers' reception system)

As a matter of fact, the issue here discussed provides a paradigmatic example of a broader one, related to the protection of individual (religious) rights in 
multi-cultural and multi-religious settings. In this regard, as stressed by some experts (Mensky, Topidi, 2016), legal empowerment is an interesting approach, since it can provide a solution against the essentialism of religious minorities.

Finally, if you look at the "success" of the process of adaptation, banishing religion is not a good strategy. The procedure of asylum request -from the phase of preparing the interview until the phase of following the possible recognition of a status of protection- can turn into a fundamental occasion to elaborate traumatic experiences, possibly through the "filter" of one's religious beliefs and experiences. A point that leads us to the fourth chapter of this part, that is devoted to the (supporting) role that religion and spirituality can play in the welcoming and integration process of (forced) migrants. 